\title{
PENETAPAN KADAR LOGAM Pb DAN Cd DALAM SEDIMEN DAN TANAMAN KANGKUNG (Ipomoea aquatica) DI SEKITAR SUNGAI BENGAWAN SOLO DI KAWASAN INDUSTRI- KARANGANYAR
}

\section{DETERMINATION OF Pb AND Cd IN SEDIMENT AND Ipomoea aquatica IN SURROUNDINGS OF BENGAWAN SOLO RIVER IN INDUSTRIAL AREA OF KARANGANYAR}

\author{
Arum Dyan Puspita, Rosita Melannisa, Andi Suhendi ${ }^{\star}$ \\ Fakutas Farmasi, Universitas Muhammadiyah Surakarta \\ adnfa@yahoo.com
}

\begin{abstract}
ABSTRAK
Air sungai Bengawan Solo digunakan untuk berbagai keperluan, khususnya pertanian dan perikanan. Keberadaan industri-industri di sekitar aliran sungai diduga telah mencemari kandungan airnya. Penggunaan air tercemar ini untuk kebutuhan pertanian dan perikanan dapat menimbulkan masalah kesehatan karena bisa terjadi bioakumulasi. Penelitian ini bertujuan untuk mengevaluasi kandungan cemaran logam $\mathrm{Pb}$ dan $\mathrm{Cd}$ pada tanaman kangkung dan tanah yang diairi sungai Bengawan Solo. Sampel tanah dan tanaman kangkung diambil secara acak dari satu lahan yang menggunakan pengairan sungai Bengawan Solo. Destruksi sampel dilakukan prosedur Standar Nasional Indonesia. Analisis logam $\mathrm{Pb}$ dan $\mathrm{Cd}$ larutan sampel dilakukan dengan menggunakan Spektrofotometri Serapan Atom (SSA). Kadar logam terukur dibandingkan dengan batas aman kandungan logam dalam pangan menurut Standar Nasional Indonesia dan dihitung nilai bioaccumulation factor (BAF). Hasil analisis menunjukkan konsentrasi $\mathrm{Pb}$ dan $\mathrm{Cd}$ dalam sedimen

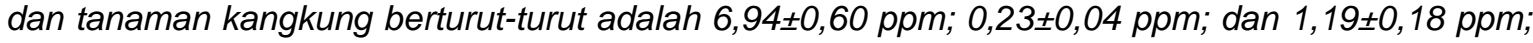
$0,32 \pm 0,01 \mathrm{ppm}$. Berdasarkan nilai ambang batas keamanan untuk $\mathrm{Pb} 0,5 \mathrm{ppm}$ dan Cd maka disimpulkan tanaman kangkung tidak aman untuk dikonsumsi. Nilai bioaccumulation factor $\mathrm{Cd}>\mathrm{Pb}$, maka disimpulkan bahwa kemampuan tanaman kangkung menyerap logam Cd lebih besar dari pada $P b$.
\end{abstract}

Kata kunci : Tanah, Tanaman kangkung (Ipomoea aquatica), kadar $\mathrm{Pb}$, kadar Cd, Bioaccumulation Factor (BAF).

\section{ABSTRACT}

River of Bengawan Solo is used for various purposes, especially agriculture and fisheries. But the existence of industries around the river presume polluted river water. Therefore the use of water for agriculture and fisheries needs will cause health problems. This study aimed are to evaluate the content of metal contaminants lead $(\mathrm{Pb})$ and Cadmium $(\mathrm{Cd})$ on soils and water spinach (1pomea aquatica) plants irrigated from river of Bengawan Solo. Samples were taken randomly from a land that using irrigation from river of Bengawan Solo. The Samples was digested by wet digestion based on national Indonesian Standard. $\mathrm{Pb}$ and $\mathrm{Cd}$ metals were analyzed by atomic absorption spectrophotometry. The concentrations of metals compared with Indonesian National Standard and calculated the value of bioaccumulation factor (BAF). The results showed the concentrations of $\mathrm{Pb}$ and $\mathrm{Cd}$ in soils and kangkong plants are $6.9365 \pm 0.5946 \mathrm{ppm}, 0.2306 \pm$ $0.0366 \mathrm{ppm}$, and $1.1925 \pm 0.1769 \mathrm{ppm}, 0.3217 \pm 0.0057 \mathrm{ppm}$ respectively. Based on Indonesian National Standard the water spinach plants are not safe for consumption, because it exceeds the safe limits of heavy metal content in food. Values of BAF Cd was higher than $P$, it means the water spinach more absorbs $\mathrm{Cd}$ easily than $\mathrm{Pb}$. .

Keywords: Sediment, Water spinach (Ipomoea aquatica), Pb, Cd,Bioaccumulation Factor $(B A F)$.

\section{PENDAHULUAN}

Banyaknya pabrik atau industri yang membuang limbahnya ke badan air atau sungai, menyebabkan tercemarnya lahan sawah yang menggunakan sungai tersebut, termasuk logam berat (Kurnia et al, 2004).Logam berat akan terakumulasi pada jaringan tubuh dan dapat menimbulkan keracunan bagi manusia, hewan, dan tumbuhan apabila melebihi batas toleransi. Timbal dan kadmium merupakan karsinogenik potensial dan menyumbangkan berbagai penyakit, terutama penyakit kardiovaskuler, 
ginjal, sistem syaraf, serta penyakit tulang dan darah (Jarup, 2003).

Tingkat pencemaran air di sungai Bengawan Solo paling tinggi dari sekian banyak sungai di Jawa Tengah. Terdapat 50 pabrik di dekat Bengawan Solo dan 42 di antaranya di wilayah Karanganyar yang meliputi pabrik tekstil, penyamakan kulit, Mono Sodium Glutamate atau vetsin, alkohol, konveksi atau batik, dan lain-lain. Pusat Penelitian Universitas Negeri Sebelas Maret, Surakarta pada tahun 2004, menemukan kandungan logam berat kromium dan kadmium di sepanjang aliran sungai Bengawan Solo yang melebihi ambang batas normal (Solikun, 2004).

Kangkung termasuk salah satu tanaman yang mudah menyerap logam berat dari media tumbuhnya (Kohar et al., 2005). Padahal kangkung banyak dikonsumsi dan sering dijumpai tumbuh atau ditanam di sekitar daerah sungai Bengawan Solo dan menggunakan pengairan yang berasal dari sungai tersebut. Oleh karena itu perlu dilakukan penelitian mengenai kandungan logam $\mathrm{Pb}$ dan $\mathrm{Cd}$ dari tanaman kangkung.

\section{METODE PENELITIAN \\ Bahan dan Alat \\ Bahan}

Tanaman kangkung, sedimen lahan kangkung, larutan standar $\mathrm{Pb}\left(\mathrm{NO}_{3}\right) 21000$ ppm, Larutan standar $\mathrm{Cd}\left(\mathrm{NO}_{3}\right)_{2} 1000$ ppm, aqua demineralisata, asam nitrat $\left(\mathrm{HNO}_{3}\right)$ pekat, asam perklorat $\left(\mathrm{HClO}_{4}\right)$.

Alat

Seperangkat instrumen Spektrofotometri Serapan Atom SHIMADZU dengan tipe AA 7000, Alat pengambil sampel, Pemanas/oven, Alat-alat gelas, Timbangan analitik.

\section{Jalannya Penelitian}

1. Pengambilan sampel

Sampel diambil dari setiap sisi lahan kemudian masing-masing dihomogenkan. Sampel kangkung diambil pada usia penanaman kurang lebih 4 minggu. Seluruh bagian tanaman diambil (dari bagian akar hingga pucuk tanaman), sedimen diambil dengan kedalaman $15 \mathrm{~cm}$ dengan menggunakan cetok stainless steel.

1. Analisis Logam

a. Preparasi sampel

Sampel kangkung dihilangkan akarnya dan dicuci dengan aqua demineralisata, dikeringkan selama 24 jam dalam suhu kamar, dikeringkan dalam oven dengan suhu $105^{\circ} \mathrm{C}$ selama 12 jam (Sobukola et al., 2010). Sampel yang telah digerus ditimbang seksama $5,0 \mathrm{~g}$, Sampel dicampur dengan aqua demineralisata sebanyak $25 \mathrm{~mL}$ dalam iodine flask, didestruksi dengan $10 \mathrm{~mL} \mathrm{HNO}_{3}$ tanpa pemanasan selama
1 jam di bawah lemari asam. Larutan sampel dipanaskan suhu $105-120^{\circ} \mathrm{C}$ selama 30 menit di atas hot plate hingga asap putih muncul dan larutan tinggal $10 \mathrm{ml}$. Setelah dingin larutan sampel ditambah $5 \mathrm{~mL} \mathrm{HNO}_{3}$ dan $3 \mathrm{~mL} \mathrm{HClO}_{4}$ kemudian dipanaskan 30 menit, larutan dibiarkan dingin, ditambahkan aqua demineralisata hingga $50 \mathrm{~mL}$, disaring dan siap dianalisis (BSN, 2006). Sampel sedimen dilakukan pengeringan dalam oven $105^{\circ} \mathrm{C}$ selama 5 jam dan diserbuk serta diayak. Kemudian dilakukan proses destruksi seperti sampel kangkung.

b. Pembuatan kurva baku

1) Pembuatan larutan baku $\mathrm{Pb}$ dan $\mathrm{Cd} 100$ $\mathrm{ppm}$

2) Pembuatan larutan baku Pb dan Cd 10 ppm

3) Pembuatan larutan seri konsentrasi

Dibuat larutan seri konsentrasi $\mathrm{Pb} 0,05$

ppm; 0,1 ppm; 0,5 ppm; 1 ppm; 2 ppm. Sedangkan untuk Cd, dibuat larutan seri konsentrasi Cd 0,01 ppm; 0,05 ppm; 0,1 ppm; 0,2 ppm; 0,4 ppm.

c. Analisis dengan SSA.

1) Analisis kualitatif

Jika pada $\lambda$ lampu katoda $\mathrm{Pb}$ atau $\mathrm{Cd}$ cuplikan memberikan absorbansi, maka sampel mengandung logam berat $\mathrm{Pb}$ atau $\mathrm{Cd}$ sesuai dengan lampu yang digunakan.

2) Analisis Kuantitatif

Teknik yang digunakan dalam analisis ini adalah metode kurva kalibrasi. Sampel yang telah dipreparasi dibaca serapannya pada SSA kemudian nilai absorbansi dimasukkan pada persamaan kurva baku $(\mathrm{y}=\mathrm{Bx}+\mathrm{A})$ sebagai nilai $y$, maka akan diperoleh nilai $x$ sebagai nilai kadar logam $\mathrm{Pb}$ atau $\mathrm{Cd}$ dalam sampel.

\section{HASIL PENELITIAN DAN PEMBAHASAN}

Sedimen dan tanaman kangkung yang diteliti, diambil dari lahan pertanian dengan luas $3 \times 4 \mathrm{~m}$ yang terletak $500 \mathrm{~m}$ dari jalan raya Palur. Lahan tersebut terletak kurang lebih 50 $\mathrm{m}$ dari sungai Bengawan Solo dengan jarak ketinggian daratan dari sungai 5-7 m. Pengairan lahan menggunakan air sungai Bengawan Solo dengan bantuan pompa. Tanaman kangkung diambil pada usia 4 minggu dan berdasarkan hasil determinasi, tanaman kangkung tersebut merupakan jenis kangkung air (Ipomoea aquatica).

Cemaran logam $\mathrm{Pb}$ dan $\mathrm{Cd}$ diukur menggunakan Spektrofotometri Serapan Atom. Analisis kuantitatif menggunakan metode kurva kalibrasi dengan persamaan $Y=0,0198 x-$ $9,5342 \times 10^{-5}$ untuk logam $\mathrm{Pb}$ dan $\mathrm{Y}=0,4976 \mathrm{x}+$ $2,2195 \times 10^{-3}$ untuk Cd.

Kandungan Logam $\mathrm{Pb}$ lebih besar dibanding logam Cd. Limbah pada sungai air Bengawan Solo dapat berasal dari limbah 
domestik dan industri di kawasan pucang sawit seperti industri cat, tekstil dan plastik. Selain dari sungai, logam $\mathrm{Pb}$ dapat mencemari tanah dari asap kendaraan bermotor dan polusi udara industri yang kemudian terbawa hujan dan meresap ke dalam tanah.

Kandungan logam $\mathrm{Pb}$ dalam sedimen 6,9365 \pm 0,5946 ppm lebih besar dibandingkan kandungan $\mathrm{Pb}$ dalam tanaman kangkung $1,1925 \pm 0,1769$ ppm. Banyaknya logam $\mathrm{Pb}$ dari sungai Bengawan Solo yang terserap ke dalam tanah. Hasil kandungan logam $\mathrm{Pb}$ diperlihatkan pada Tabel 1.

Tabel 1-Kandungan Logam Pb Dalam Sedimen dan Tanaman Kangkung

\begin{tabular}{ccccc}
\hline Sampel & $\begin{array}{r}\text { Kons. } \\
(\mathbf{p p m})\end{array}$ & Rerata & SD & BAF \\
\cline { 1 - 2 } Sedimen & $\begin{array}{l}6,5750 \\
7,6227\end{array}$ & 6,9365 & 0,5946 & \\
& 6,6118 & & & \\
\cline { 1 - 2 } Tanaman & 1,0080 & & & \\
& 1,2090 & 1,1925 & 0,1769 & \\
& 1,3606 & & & \\
\hline
\end{tabular}

Kandungan logam Cd dalam tanaman kangkung 0,3217 \pm 0,0057 ppm lebih besar dibandingkan kandungan $\mathrm{Cd}$ dalam sedimen 0,2306 \pm 0,0366 ppm Kandungan logam Cd lebih tinggi dalam tanaman. Kandungan logam dalam sedimen dan tanaman kangkung diuji dengan menggunakan independen t test dan menunjukkan adanya perbedaan bermakna (signifikan). Hasil kandungan logam Cd diperlihatkan pada dan Tabel 2 .

Tabel 2-Kandungan Logam Cd Dalam Sedimen dan

\begin{tabular}{|c|c|c|c|c|}
\hline Sampel & $\begin{array}{l}\text { Kons. } \\
\text { (ppm) }\end{array}$ & $x$ & SD & BAF \\
\hline & 0,2728 & & & \multirow{4}{*}{1,3951} \\
\hline Sedimen & $\begin{array}{l}0,2126 \\
0,2065\end{array}$ & 0,2306 & 0,0366 & \\
\hline & 0,3151 & & & \\
\hline Tanaman & $\begin{array}{l}0,3250 \\
0,3250\end{array}$ & 0,3217 & 0,0057 & \\
\hline
\end{tabular}

Kemampuan tanaman menyerap logam berat dari dalam tanah dievaluasi dengan nilai BAF (bioaccumulation factor). Nilai BAF logam Cd $(1,3951)>\mathrm{Pb}(0,1719)$. Akumulasi logam dalam tanaman tergantung pada kandungan logam dalam tanah, jenis logam, unsur kimia tanah, $\mathrm{pH}$ tanah, dan spesies tanaman. $\mathrm{pH}$ tanah memiliki pengaruh terbesar dari setiap faktor tunggal pada kelarutan atau retensi logam dalam tanah (Ghosh dan Singh, 2005).
Hasil pengukuran, $\mathrm{pH}$ tanah diperoleh nilai 5,53 yaitu $\mathrm{pH}$ yang cukup asam dalam penyerapan logam dari tanah ke tanaman. Tanah yang asam akan melarutkan mineral dan logam dalam tanah, termasuk logam yang toksik (Darmono, 1995). Nilai BAF digunakan untuk mengetahui kemampuan tanaman dalam menyerap dan mengakumulasi logam dari tanah ke bagian tubuhnya. Nilai BAF yang lebih dari 1 menunjukkan akumulasi logam dari tanah ke tanaman cukup besar.

Kandungan logam $\mathrm{Pb}$ dan $\mathrm{Cd}$ yang terdapat dalam tanaman kangkung melebihi batas aman untuk dikonsumsi. Menurut BSN (2009) batas toleransi aman bagi buah dan sayuran yang dikonsumsi adalah $0,2 \mathrm{mg} / \mathrm{kg}$ untuk $\mathrm{Cd}$ dan 0,5 mg/kg untuk $\mathrm{Pb}$. Hal ini perlu mendapatkan perhatian kepada masyarakat dalam mengkonsumsi dan memanen sayuran dengan pengairan sungai Bengawan Solo, serta perhatian industri di kawasan Karanganyar kepada lingkungan sekitar.

\section{KESIMPULAN}

Berdasarkan hasil penelitian yang telah dilakukan maka dapat disimpulkan bahwa:

1. Terdapat logam $\mathrm{Pb}$ dan $\mathrm{Cd}$ dalam sedimen dan tanaman kangkung (Ipomoea aquatica) yang ditanam di sekitar sungai Bengawan Solo, kawasan industri Karanganyar dengan kadar logam $\mathrm{Pb}$ dan $\mathrm{Cd}$ dalam sedimen dan tanaman kangkung adalah 6,9365 \pm 0,5946 ppm; 0,2306 \pm 0,0366 ppm; dan 1,1925 \pm 0,1769 ppm; 0,3217 \pm $0,0057 \mathrm{ppm}$.

2. Hasil yang melampaui batas cemaran logam dalam sayuran, sehingga kangkung tersebut tidak aman untuk dikonsumsi.

\section{SARAN}

1. Perlu dilakukan penelitian kandungan logam berat $\mathrm{Pb}$ dan $\mathrm{Cd}$ pada tanaman konsumtif lainnya yang ditanam di sekitar sungai Bengawan Solo, kawasan industriKaranganyar.

2. Perlu dilakukannya sosialisasi penelitian kepada para petani yang menanam sayuran pertaniannya di sekitar sungai Bengawan Solo serta warga sekitar.

3. Perlu adanya tindakan tegas dari pemerintah setempat kepada pemilik industri di kawasan sungai Bengawan Solo mengenai limbah cemaran logam berat

\section{DAFTAR PUSTAKA}

BSN, 2004, Standar Nasional Indonesia, Cara uji kadmium (Cd) secara destruksi asam dengan Spektrofotometer Serapan Atom (SSA), Badan Standarisasi Nasional, Jakarta.

BSN, 2009, Standar Nasional Indonesia, Batas Maksimum cemaran Logam Dalam Pangan, Badan Standarisasi Nasional, Jakarta. 
Darmono, 1995, Logam Dalam Sistem Biologi Makhluk Hidup, 15, 18, 62, Universitas Indonesia Press, Jakarta.

Ghosh M., and Singh S.P., 2005, A review on Phytoremediation of Heavy Metals and Utilization of Its Byproducts, Biomass and Waste Management Laboratory, School of Energy and Environmental Studies, Faculty of Engineering Sciences, Devi Ahilya University, Indore, India. (Online) http://www.ecology.kee.hu/pdf/0301 001018.pdf.

Jarup, L., 2003, Hazards of Heavy Metal Contamination, British Medical Bulletin, 68, 167-182.

Kohar, I., Poppy H.H., dan Imelda I.L, 2005, Studi Kandungan Logam Pb Dalam Tanaman Kangkung Umur 3 Dan 6 Minggu Yang Ditanam Di Media Yang Mengandung Pb. Makara Sains 9, No. 2.

Kurnia, U., Suganda H., dan Nurjaya, 2004, Teknologi pengendalian Pencemaran Lahan Sawah, Laporan Penelitian Pusat Penelitian dan Pengembangan Tanah dan Agroklimat, Badan Penelitian dan Pengembangan

Bogor.http://balittanah.litbang.deptan.go.id/dokumentasi/prosiding/mflp2006/irsal.pdf.

Pertanian,

Sobukola, O. P, O. M. Adeniran, A. A. Odedairo and O. E. Kajihausa, 2010, Heavy Metal Levels Of Some Fruits And Leafy Vegetables From Selected Markets In Lagos, Nigeria, African Journal of Food Science. 4(2), 389 - 393

Solikun, 2004, Sungai Bengawan Solo Tercemar Logam Berat (Online), (http://berita.liputan6.com/daerah/200408/84143/class=\%27vidico\%27, diakses pada 19 Desember 2010). 